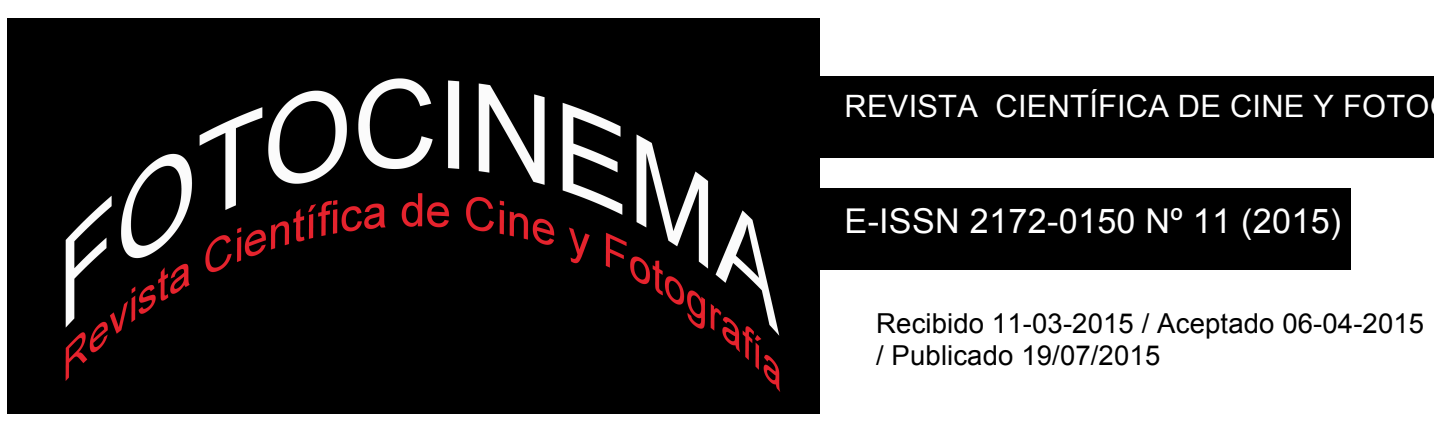

\title{
POR UNA SEMIÓTICA DEL SELFIE EN LA CULTURA VISUAL DIGITAL
}

A SEMIOTICS OF SELFIE IN THE VISUAL DIGITAL CULTURE

\author{
Manuel A. Broullón-Lozano \\ Universidad de Sevilla, España \\ mbroullon@us.es
}

\section{Resumen:}

En primer lugar, el fenómeno selfie consiste simplemente en volver del revés la sintaxis fotográfica con el fin de hacer coincidir en la misma instancia al fotógrafo y al objeto fotografiado. No obstante, más allá de esta operación, el selfie tiene que ver con el régimen escópico de la sociedad de comienzos del siglo XXI. El presente ensayo analiza un archivo de fotografías digitales tomadas y publicadas en Internet durante el año 2014, todas ellas compuestas de acuerdo con esta estructura enunciativa autoconsciente. En último término, se tratará de establecer una tipología cultural semiótica en torno a la estructura del ver y del ser visto a través de la web 2.0.

\begin{abstract}
:
First of all, the selfie phenomena consists on turning inside the photoghraphic syntax, in order to concentrate into the same instance the photographer and the object of the photography. In addition to this, it has to deal with the visual structure of the society at the begining of the XXIst century. On that way, this essay may analyze some digital pictures which has been taken and published on the Internet during the year 2014 which have been composed according to this self conscient enunciation. At least we may be able to build a semiotic cultural typology about the structure of watching and being watched through the web 2.0.
\end{abstract}

Palabras clave:

selfie; sí mismo; cultura visual digital; fotografía digital; panopticon; semiótica

Keywords:

Selfie; Self; Visual Digital Culture; Digital Photography; Panopticon; Semiotics. 


\section{Introducción y metodología}

Una acción sencilla: gire su teléfono móvil, active la cámara trasera, arréglese el pelo, no deje de sonreír y apriete el botón. Solo o acompañado, durante un viaje o en el día a día; en la red de redes, millones de usuarios han dado rienda suelta a esta práctica fotográfica denominada selfie. Moderna, narcisista, exhibicionista... Dicha práctica se asienta sobre una comportamiento humano capaz de modificar el ecosistema comunicativo (Levin, 2014) pero que, al mismo tiempo, replantea el modo de ser en el mundo, de representarse, de conocerse y re-conocerse en un largo proceso productivo de textos icónicos cuya particularidad radica sobre los "factores subjetivos" patentes en "el proceso de la toma fotográfica y su difusión posterior” (Canga, 2015, p. 402). Lo cierto es que en la iconosfera actual se ha producido un cambio en la relación establecida entre la cámara de fotos, el fotógrafo y el objeto fotográfico, de manera que, girando sobre sí mismo, el dispositivo tecnológico pasa a ser un espejo en el que se reflejan tanto el retratista como el retratado. Si los dos actantes coinciden sobre el mismo sujeto de la enunciación fotográfica, ¿̇qué consecuencias implica sobre el fenómeno de representación icónica?

El presente trabajo se propone realizar un análisis del fenómeno selfie por medio del método de la semiótica de la cultura (Lotman, 2000): elaborar tipologías culturales con el objetivo de comprender las prácticas comunicativas en el seno de la vida social de los textos. Con las herramientas propias de la semiótica generativa (Greimas y Courtés, 1982, pp. 191-198) tales como el problema del aparato formal de la enunciación (Benveniste, 1977, pp. 82-94) o de la veredicción, se trata de formular una doble pregunta: "quién dice" y "cómo significa la representación icónica" en un enunciado fotográfico de esta clase autorreferencial.

Para ello, en primer lugar, se tratará de elaborar una tipología cultural del régimen escópico en la cultura occidental, esto es, la estructura predicativa del ver y la reflexiva del ser visto. Como es propio de la semiótica actual, en el cometido de realizar la representación semiótica de un concepto o de una estructura como es el régimen escópico, "no se propone construir el semema 
de la lengua o en los textos" sino establecer "el esquema semiótico tal y como se presenta a través del conjunto de los conceptos, las situaciones y las prácticas" que se postulan como dicho concepto en el interior de una cultura (Fontanille, 2014, p. 141). Es por ello por lo que en la páginas siguientes se estudiará un archivo de textos culturales que contribuirán a convertir nociones polisémicas como pueden ser "visión”, "vigilancia” o "sí mismo" (self) en configuraciones semióticas.

Más adelante se propondrá un análisis semiótico del aparato formal de la enunciación de una serie de fotografías que respondan a estas características enunciativas del self firmadas por agentes sociales de especial relevancia, como es propio del synopticon (concepto que se desarrollará más adelante). Finalmente, y tras plantear cuestiones centrales como son la autenticidad y la veredicción, se propondrán algunas conclusiones a partir de los rasgos observados durante el análisis para matizar, si procede, la configuración semiótica propuesta en un principio.

\section{Tiresias contra Narciso}

La mitología griega ha concedido un papel esencial al sentido de la vista $(o \pi \tau \iota \kappa \omega v)$ y a los signos que de ella se derivan. Por ello, cuando Edipo ve con claridad la magnitud de su incestuoso pecado (el potente efecto de la

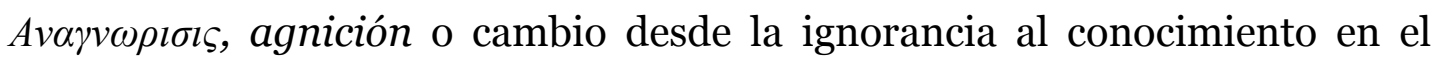
género trágico: Aristóteles, 1974, p. 164), el castigo autoimpuesto consiste en arrancarse los ojos. Con este efecto patético, Sófocles (2014, p. 97), nos enseña que la cuestión del poder/saber ver no solo se refiere, lógicamente, a las imágenes percibidas por el ojo humano, sino de forma general, al conocimiento que estas podrían proporcionar. Así el profeta Tiresias, aun ciego desde muy joven, ha obtenido de los dioses el don de la videncia. Esto es: la capacidad de revelar imágenes que, según la definición aportada por el DRAE, “están fuera de lo que se considera común”. Por ello Tiresias es visionario y Edipo ciego e inconsciente ante unos secretos funestos que el ojo humano no puede percibir: “iAy, ay! iQué terrible es tener clarividencia cuando [esta] no aprovecha al que la tiene!" (Sófocles, 2014, p. 25) 
Los dioses helénicos de la Ilíada, además, todo lo ven, todo lo observan desde la colosal altura del Monte Olimpo: "sentados en junta/ [...] en el áureo pavimento". El poeta Homero (IV 5-20; 1998, p. 2) describe dicho panteón al modo de una tribuna (poder ver) desde la que, divididos durante la guerra entre troyanos y aqueos, los dioses juegan con el destino de los mortales: "y en cuanto a nosotros, manifestemos cómo serán estas labores:/ o bien otra vez guerra mala y terrible porfía levantamos/ o amistad en medio de ambos bandos tiramos,/ si así esto para todos dulce y grato resultara” (1998, p. 3). En la mitología ática, el principio de intervención divina estructura el mundo como en la metáfora moderna de la "sociedad disciplinaria" (o tal vez esta intentara elevar al hombre poderoso a la categoría de dios olímpico; Foucault, 1994, pp. 199-230), en donde "unos pocos vigilan a muchos" (Mathiesen, 1997, p. 217), de manera que sus acciones y pensamientos están controlados por los hilos de seda que tejen y finalmente cortan las Moiras (Molpal). "Zeus, que sopesa las vidas de los hombres e informa a las Moiras de sus decisiones puede, según dicen, cambiar de idea y salvar la vida de quien le plazca" (Graves, 1985, p. 15).

En contra de esta puesta en escena del mundo como prisión laberíntica en donde el individuo queda a merced de los caprichos de los dioses, Ovidio nos presenta en la Metamorfosis (2004, pp. 116-125) al obstinado e individualista Narciso: "al alcanzar los dieciséis años de edad, su camino estaba cubierto de amantes de ambos sexos que habían sido cruelmente rechazados" (Graves, 1985, p. 94). Pero ni siquiera aquel que hizo volverse hacia sí todos los ojos del mundo -incluso los de los altivos dioses- escapa al extraordinario don del ciego Tiresias (saber ver), quien había predicho en un oráculo que el joven alcanzaría la longevidad si (si y solo si) nunca llegaba a verse a sí mismo. Es decir: si jamás accedía a una percepción del self, a la reflexividad del "sí mismo ante el espejo" -en palabras del neurólogo y psiquiatra Carlos Castilla del Pino- en la que el observador "se hace objeto para sí mismo" (Segarra, 2010, p. 267).

En el universo mitológico, la autopercepción es un asunto peligroso: Narciso "se enamoró de su propia imagen" en cuanto esta le fue revelada (Graves, 
1985, p. 95). El joven languideció, enfermó... porque su reflejo se convirtió en un signo independiente, esquivo, inasible, tanto para la ninfa Eco (o para el pretendiente homosexual Aminias) como para él mismo. Incluso después de su muerte siguió hechizado, mirando su rostro en las tristes aguas de la laguna Estigia. Quizás por ello no nos extraña que en el cuadro de Michelangelo Merisi da Caravaggio (1571-1610) el reflejo de Narcissus no se corresponda con su delicada imagen original, sino con el rostro avejentado de un hombre de mediana edad. Esta anécdota que plantea la incierta dialéctica entre el original y la copia, lejos de ser baladí, no se nos escapará en las páginas siguientes.

\section{Panopticon, synopticon}

Narciso es interesante porque, en su devenir signo, inaugura unas relaciones de mirada capaces de condicionar la estructura del mundo que lo rodea. Cuando de forma irresistible atrae los deseos de Eco o de Aminias, Narciso provoca en torno a sí un sistema de interacciones que contraviene la jerarquía olímpica. Frente al panopticon de Jeremy Bentham (1978; asimilable a la imagen del "Big Brother" en la novela de George Orwell 1984: “iel gran hermano te ve y te vigila!”), genera la estructura contraria: el synopticon, en donde muchos (las masas) ven a unos pocos a propósito de un aspecto que los concita y los condensa en torno a sí: "the concept is composed of the Greek Word syn which stands for 'together' or 'at the same time' and opticon, which has to do with the visual” (Mathiesen, 1997, p. 219). Pero nótese que el complejo juego de miradas de Narciso va incluso más allá de la definición de este criminólogo danés: es sujeto y objeto en relación con todo el cosmos, pero también respecto de sí mismo... a condición de que su imagen permanezca siempre inalcanzable.

La era digital -con el abaratamiento y puesta a punto de las tecnologías de la imagen- organiza una estructura visual narcisista similar a la del synopticon. Ello no quiere decir que el panopticon haya sido sustituido, es más, coexisten el uno en relación con el otro (Mathiesen, 1997, p. 223). Pero lo hacen desde una desconfianza en torno a ciertos signos de alarma emitidos por las 
instancias de poder - a través de las instituciones de seguridad o espionaje y del terrorismo- que podrían ejercer de forma más o menos lícita unas “prácticas de vigilancia” y unas “políticas de visibilidad” (Lyon, 2006, p. 35).

Tomando la siempre vigente e irónica distinción entre "apocalípticos" e “integrados" de Umberto Eco (2003), hoy intuimos entre aquellos primeros a los celosos de su privacidad y de su imagen que, temerosos como Edipo, renuncian a ver y a ser vistos. Los apocalípticos contratan a empresas privadas para borrar su huella digital de la red de redes: el "derecho a ser olvidados" cuando "el pasado pesa como una losa, cuyo peso en el presente resulta insoportable” (Herrán Ortiz, 2014). El apocalíptico sospecha que la red es un instrumento del panopticon para extender y organizar lo que puede ser visto y controlado por las instancias del poder, especialmente, las económicas, que aprovecharían estos datos para generar estrategias en un mercado segmentado. Bajo este punto de vista, no sólo el derecho a la privacidad de la correspondencia sino también las libertades de expresión e información estarían amenazadas en función del adagio latino "verba volant, scripta manent”, oportuna definición para gran archivo global que es la red.

Frente ellos, los "integrados" son gurús entusiastas de los social media (obsérvese que actualmente tanto la literatura especializada como el habla coloquial evitan la antigua denominación mass media) que bien podrían enumerar diez razones para convencer de la idoneidad de contar a través de Twitter qué estás haciendo o de hacerte un autorretrato en tus lugares favoritos. Estos canales serían -del mismo modo que Narciso busca su espejo en el Aqueronte- medios privilegiados para dar rienda suelta a la libertad de expresión (producción), a la libre elección (acceso) entre una pluralidad de información disponible en el gran archivo de la red.

\section{El self en la era digital}

Más allá de ironías, lo cierto es que el giro 2.0 de las interfaces gráficas y de la experiencia de usuario en la world wide web ha terminado por privilegiar la enunciación en primera persona como el modelo que le es propio. En 
consecuencia, dos de los rasgos predominantes en el discurso digital son 1) la construcción del self y 2) la palabra clave "social”. Así, Facebook, no solo nos pregunta antes de compartir una nueva publicación “¿qué estás pensando?”; también ha incluido utilidades destinadas a contar qué estás haciendo, leyendo, viendo; dónde y con quiénes; incluso “cómo te sientes”. Incardinado en estas dinámicas que tienden al presente como tiempo verbal enunciativo propio de las redes sociales, el selfie como constructo icónico se ha convertido en "an increasingly exact, diffuse and contextually determined representation of individuals within highly articulated networks of actors" (Levin, 2014). Es por ello por lo que Facebook cambió el formato "muro" (cajón de sastre o cuaderno de notas en donde todo cabe) al de "biografía", mejor dicho, "relato autobiográfico".

Estas interfaces ejercen una mediación similar a la del opaco espejo de Narciso en el cuadro de Caravaggio: el problema de la autorrepresentación cuando el original y la copia resultan ser imágenes diversas. De otra parte, conviene recordar que tal es la quintaesencia del texto artístico: "la posibilidad de complicar las relaciones entre la primera y la tercera persona” (Lotman, 1998, p. 57). La estetización del sujeto en el entorno digital genera una relación ambigua y especular al modo de arenas movedizas entre los espacios "de los nombres propios y de la narración objetiva en tercera persona” (Lotman, 1998, p. 57). Cuando aquellos primeros aparecen en el texto artístico -empleando formas enunciativas como la confesión o incluso la plegaria- aspiran a representar la verdad subjetiva; pretenden construir una potente impresión de realidad en el seno de la maquinaria discursiva: yo, conmovido, te confieso algo a ti en secreto, mi lector confidente, desde la intimidad de estos signos a los que solo tú y yo tenemos acceso.

De otra parte, la lectura individual, al igual que las luces de gas de los teatros en los que se representaba la ópera verista (en donde, precisamente, la emoción surgía de un pacto entre palabra y música capaz de expresar los más profundos abismos humanos) garantiza ese hablar íntimo y a media voz en donde se dirigen a mí y solo a mí, pues en la penumbra me olvido de todo lo que ha quedado oscurecido a mi alrededor (Mathiesen, 1997, 222). Más allá 
de la actitud del voyeur "el ejecutor para mí es él, pero yo fundo todos sus discursos y sentimientos en mi yo" (Lotman, 1998, p. 59). Las tecnologías de la recepción digitales tienden a este mismo oscurecimiento del contexto en el acto de lectura, sea a través del objeto de uso personal (teléfono móvil, tablet), sea por su ubicación en espacios privados (el ordenador personal, a menudo portátil, instalado en el dormitorio). Entonces, y bajo este punto de vista, la mirada, siquiera el vistazo de un desconocido a la pantalla de mi teléfono móvil incluso en un espacio público, supone a todas luces un gesto de indiscreción.

Por la otra parte - la emisión del signo-, la proyección del self a través de los dispositivos fotográficos (fijos o en movimiento) se establece a partir de una “triple deixis” de la primera persona: yo-aquí-ahora (Vázquez Medel, 2003, p. 24):

Hoy, en una época en la que cada día se suben a Facebook más de doscientos millones de imágenes, y se guardan otras cuantas en los discos duros de los ordenadores del mundo [...], las fotos, manipuladas con los filtros de Instagram para dotarlas de la tesitura del tiempo que pasa, se convierten en balbuceos retro de un pasado sumido en los estertores del simulacro. Y sí, todo pasado es simulacro, pero algunos fueron simulacro de primera mano ${ }^{1}$. (Cardona Echeverri, 2013, p. 67).

Si se acepta que en la era digital el signo icónico, aun cuando es percibido como documento fidedigno, no puede ser definido en términos exclusivamente demostrativos o de sinceridad, sino como un simulacro o bien de transparencia o bien de complicidad con el destinatario, entonces el problema del self se convierte en el de la imaginería de la primera persona, la construcción de una puesta en imagen (cuando no en escena) del yo, del aquí y del ahora.

Lo que se reconoce como verdadero -recuérdese el cuadro de las modalidades veredictorias de Greimas y Courtés (1982, p. 434)- no solo tiene que serlo. La verdad también tiene que ser y (a)parecer como tal. La

\footnotetext{
${ }^{1}$ La cursiva es nuestra. A este respecto surge el concepto de "autenticidad" frente al de "originalidad" en los tiempos post-benjaminianos de la reproductibilidad técnica digital.
} 
verdad, de existir esta, ha de consistir "en un enunciado de estado interdependiente de un sujeto modal" que garantice su "manifestación" (1982, p. 434). Por ello, las tecnologías fotográficas destinadas a un uso social en la red se han adaptado a la inclusión de un cierto tipo de sujeto modal (un sujeto modal egocéntrico) en el enunciado a través de dispositivos como la webcam, la cámara trasera del teléfono móvil y de la tablet, la pantalla reversible en la cámara de fotos, etcétera. La inclusión en la composición visual del yo supone, volviendo sobre Lotman (1998, p. 57), la construcción estilística del nombre propio.

\section{Del self al selfie}

Por todos es sabido que durante la gala de entrega de los Premios Oscar de la Academia de Cine americana la noche del 2 de marzo de 2014, la humorista y presentadora de televisión Ellen De Generes tuvo la ocurrencia de acercarse hasta la primera fila del patio de butacas del teatro Kodak con el fin pedir a los actores nominados -unos elegantísimos Jennifer Lawrence, Channing Tatum, Meryl Streep o Bradd Pitt entre otros- que se hicieran todos juntos una foto de grupo con un teléfono móvil personal, que ella misma ponía a disposición ${ }^{2}$. Aparentemente, dentro de la espontaneidad que permiten los guiones de una gala emitida y seguida con avidez en todo el mundo, no dejaba de ser una acción simpática a la par que frívola y narcisista. Pero la imagen trasciende: De Generes prometió subirla de inmediato a la red social Twitter, proponiendo a "los muchos que ven a unos pocos" (synopticon) el desafío de batir el récord de retweets. Y así sucedió: 779.295 retweets en treinta minutos, por encima de los 763.035 alcanzados por Barack Obama durante la campaña de reelección el 7 de noviembre de 2012. Por si fuera poco, la presentadora de shows televisivos declaró que aquella imagen se había convertido por méritos propios "the best photo ever".

El selfie se define entonces como un autorretrato fotográfico, individual o de grupo, en el cual uno de los retratados sostiene y acciona el dispositivo de

\footnotetext{
${ }^{2}$ http://twitter.com/TheEllenShow/status/440322224407314432/photo/1
} 
captura. Esta práctica aparentemente banal se ha convertido en hábito cotidiano en los usuarios de smartphone y redes sociales: el deseo de ser visto y de ubicarse en la posición privilegiada del synopticon. Sin embargo lo más interesante no es el uso privado, sino el cultivo del selfie por parte de agentes sociales con una cierta capacidad de influencia, en cumplimiento del mandato de cercanía, proximidad y naturalidad que dictan las vigentes leyes del marketing, de las relaciones públicas y de la propaganda política. Como en el caso de Tiresias, lo interesante de una imagen no es sólo su entidad icónica sino que lo que nos permite conocer en términos de saber y poder ver.

\section{Espontaneidad vs. Relaciones Públicas}

El Papa Francisco y su gabinete de asesores conocen bien estas leyes y por ello el pontífice romano no sólo se deja retratar por fotógrafos no oficiales, sino que detiene el protocolo oficial para hacerse un selfie con jóvenes católicos que, por supuesto, aparecería segundos después en Twitter3. La imprevisibilidad (rompe con el protocolo, con la sintaxis normativa y previsible dentro de un orden discursivo religioso) y la inmediatez (gracias a la conexión $3 \mathrm{G}$ y $4 \mathrm{G}$ ) son dos claves que podemos extraer de este selfie pontificio. No perdamos de vista que, efectivamente, Francisco ha emprendido una campaña de relaciones públicas con el fin desmontar la imagen del Papa como príncipe. Por ello se sitúa, desde el punto de vista de la composición fotográfica, al mismo nivel de los fieles.

La clase política más influyente a nivel internacional también es pródiga en esta técnica: el vicepresidente de los Estados Unidos Joe Biden subió a su perfil de Instagram un selfie tomado por él mismo durante un trayecto en coche oficial con el presidente Obama: "Found a friend to join my first selfie on Instagram. Thanks for following and stay tuned"4. Evidentemente, en la

\footnotetext{
${ }^{3}$ http://twitter.com/FabioMRagona/status/373177674107072512

${ }^{4}$ La cursiva es nuestra.

http://instagram.com/p/m3z66SlwW4/?utm source=partner\&utm medium=embed\&utm campaign= photo Lógicamente, la Casa Blanca se hace eco rápidamente y retuitea la fotografía del vicepresidente: http://twitter.com/WhiteHouse/status/456603722101964800/photo/1
} 
estructura óptica del mundo de hoy, presidente y vicepresidente de los Estados Unidos son lo más cercano a las parcas que tejen los hilos de la humanidad desde su posición privilegiada de vigilancia. Sin embargo, los poderosos ya no se hacen retratar en demostración de su poder, como lo había hecho Luis XIV en el cuadro de Hyacinthe Rigaud. Por el contrario se apresuran a autorretratarse como seres humanos con costumbres populares que, según se lee en la segunda parte del pie, solicitan ser vistos (synopticon) y estar en contacto para prolongar y fijar dicho contacto visual. Una segunda característica del selfie es que constituye un eslabón en una cadena de continuidad narrativa, de manera que solicita la atención (Biden nos convida a ser sus "followers") y aspira a suscitar un interés de cara a futuras comunicaciones ("stay tuned”).

Durante el mundial de fútbol de Brasil 2014, la canciller alemana Angela Merkel también hizo lo propio junto al futbolista Podolski durante su visita a Río de Janeiro5. El sentimiento nacionalista que aflora en este tipo de competiciones deportivas así lo exigía. De aquí se desprende otro rasgo: la oportunidad con respecto a un contexto informativo y pragmático de actualidad en la esfera pública. Por fortuna este acto de exaltación del espíritu nacional distaba en significado y sentido de la celebración de la selección alemana tras su victoria en la copa del mundo con el ya famoso "baile de los gauchos", tristemente famoso por xenófobo. En esta contraposición encontramos otra clave: la aparente inocencia del selfie frente a otras manifestaciones y expresiones comunicativas, la supuesta candidez que otorga la evidencia de la imagen en su ser-ahí frente al enunciado verbal, velo de lo implícito.

De aquí se desprende también el carácter fronterizo del selfie en lo que se refiere a la producción de comunidades de sentido. Cuando la oportunidad es un elemento dominante, mediante su deixis personal (primera, segunda y tercera persona; singular o plural), el selfie eleva una frontera: la del “nosotros”, que estamos aquí en un instante único, frente al "ellos”, a quienes nos mostramos y pedimos que nos observen.

\footnotetext{
${ }^{5}$ http://twitter.com/Podolski10/status/488457897614278657/photo/1
} 
Un último ejemplo: el presidente Rajoy, cuya estrategia de relaciones públicas consiste en una muy medida prudencia entre la cantidad y la forma de sus comparecencias, participa de esta moda sobre todo cuando se trata de un contexto deportivo. De hecho, su único selfie conocido hasta la fecha es el publicado en Twitter por el jugador de baloncesto Serge Ibaka ${ }^{6}$. En otras ocasiones resulta curioso que la imagen que ha trascendido -como es el caso de la fotografía aparecida en el diario Público7- no es la tomada por el smartphone que sujeta una simpatizante del Partido Popular, sino la de un fotógrafo externo. En consecuencia, cuando no es compartido inmediatamente a un público cuantificable, el selfie no llega a realizarse, puesto que no cumple con su función demostrativa y social: yo (o nosotros), aquí, ahora. De acuerdo con la experiencia fundacional de Ellen De Generes el destino natural del selfie consiste la exposición pública con el máximo impacto posible cuantificable a través de retweets, de menciones y de comentarios derivados. El selfie persigue por tanto apoyar una estrategia de notoriedad pública, de relevancia social.

\section{Remix vs. autenticidad}

Una definición provisional y un tanto malévola de Internet podría ser la aportada por Roman Gubern (2009) bajo metáfora del vertedero: "la pantalla de computadora ofrece una catarata textual [...] en la que caben dos tipos de mensajes: el mensaje personalizado y la forma más popular de internet, que es la red como un vertedero público global”. A pesar de que a esta sentencia le subyace un prejuicio claramente apocalíptico, la imagen del exceso caótico es válida para explicar el problema actual de la iconosfera: encontrar la imagen perfecta sería como encontrar una aguja en un pajar. Otra característica del selfie es, por tanto, que su autor no copia y pega, ni enlaza, ni está dispuesto a dejarse llevar por el creer saber (creer ver en este caso) de otros que han colgado imágenes en la red. Esto era válido en la retórica de

\footnotetext{
${ }^{6} \mathrm{http}: / /$ twitter.com/sergeibaka9/status/494825307409772545/photo/1

${ }^{7} \mathrm{http}$ ///imagenes.publico-estaticos.es/resources/archivos/2014/5/17/1400337750221 rajoy-barnaeuropeas-selfie_642x300.jpg
} 
Google Images, en la cultura del remix, en donde apropiacionismo incluso ha llegado a ser una práctica con completa legitimidad artística.

El autor del selfie, por el contrario, acude él mismo a buscar la imagen. Y entonces su presencia adquiere una función similar a la de la firma: la garantía de autenticidad. No le basta con hacer copy-paste de la fotografía del Big Ben o de La noche estrellada de Van Gogh que más le guste: él mismo la produce... y aparece en ella hasta el punto de que en el espacio museístico "las cámaras de los teléfonos móviles no hacen más que añadir una nota absurda al caos, porque miles de visitantes dan la espalda al cuadro que en teoría han ido a ver para fotografiarse con él” (Altares, 2014).

Entonces el encuadre modifica su estructura: el retratista está en disposición de colocarse en escena y tiene la posibilidad (al menos potencial) de ser visto por muchos en el synopticon. Lo que antes era objeto de atención e incluso de culto, ahora queda a la espalda del espectador, al tiempo que este pasa a formar parte de la composición visual como un estrato más en el encuadre fotográfico.

\section{Retórica del selfie: vigilancia y control del self}

La retórica del selfie se basa por tanto en una enunciación demostrativa en primera persona: yo demuestro, por la evidencia de la imagen, que estoy aquí haciendo tal cosa; y por eso tengo que aparecer necesariamente en primer plano. Por ello el selfie se basa en la afirmación de la individualidad, cuando no del ego. Entonces también está asociado a unas ciertas construcciones de la belleza masculina y femenina en enunciados fotográficos de carácter denotativo del desnudo (socialmente considerado decente cuando incluye el busto y las piernas de la mujer y el torso del hombre) en lugares asociados a la consecución de esa belleza, especialmente gimnasios y tiendas de ropa. La estrategia de promoción individual pasa 1) por una espectacularización de la cotidianeidad y 2) por una exaltación del cuerpo. El vestuario del gimnasio no tiene nada de especial, pero el hecho de que una celebrity pose en él no hace sino reforzar esa imagen de estrella de carne y hueso perseguida por el 
sujeto de la enunciación. De acuerdo con la tipología de las funciones del lenguaje enunciada por Roman Jakobson (1984, p. 353), la función del selfie es netamente referencial, denotativa o cognoscitiva: se dirige directamente hacia el contexto del mensaje (efectivo o simulado), lo que garantizaría su articulación veredictoria entre parecer y ser o entre parecer y no-ser. La segunda figura de la triple deixis (el "aquí" del selfie frente al allí y al allá) se convierte en ese contexto.

En su estructura compositiva, el dispositivo y el enunciador aparecen enfrentados. La técnica del selfie presenta el problema de que los límites de su encuadre dependen de la longitud del brazo de quien se autorretrata. $Y$ es que, "para ser considerado como tal, el selfie debe estar realizado por la mano del autor, el cual desempeña a su vez la función de modelo" (Canga, 2015, p. 402). Ellen de Generes incluso reconoció este inconveniente en el selfie fundacional, en cuyo pie de foto se puede leer: "if only Bradley's arms was longer...”. Lo cual conduce en ocasiones a una aberración óptica de los rasgos faciales: ojos separados y saltones, fosas nasales abiertas, dentaduras imperfectas, papadas, etcétera... Ahora bien, subsanar la aplanada perspectiva del selfie es sencillo: basta con colocarse frente a un espejo. Entonces el efecto de autenticidad se duplica en tanto que la imagen confirma la unión corpórea entre el enunciador y el dispositivo fotográfico, el cual aparecerá incluido también en la composición. Por este mismo motivo el selfie también se puede simular, y es posible aprovechar el despertar de la siesta de la mascota para colocarle el smartphone entre las patas y fingir la experiencia de usuario del lindo animal.

Otra opción, la adoptada especialmente por los turistas orientales, consiste en colocar el teléfono o la tablet en el extremo de un bastón que prolonga la extensión del brazo. Si bien en occidente este ingenio ya se había utilizado con las cámaras deportivas GoPro (cuya lente angular de ojo de pez provocaba una aberración óptica notable) el sistema del bastón con smartphone supone una franca ventaja en lo que se refiere al control de la propia imagen corporal y, sobre todo, del rostro. 


\section{Discusión y conclusiones}

Tomando como clave la concepción liminar y deíctica del selfie (yo/nosotros, aquí y ahora; frente a vosotros/ellos, ahí/allá y antes/después) cabría preguntar si ese control de la autorrepresentación a partir del discurso fotográfico digital podría ser considerado como un logro en lo que se refiere a la libre construcción del self, la autopercepción del sí mismo ante el espejo y ante la sociedad. Recuérdese que la soberbia de Narciso consiste en su conquista de la posición privilegiada en la estructura social, hasta entonces reservada a los dioses. Por tanto, pasa de ser vigilado (objeto de la mirada de otros más poderosos, panopticon) a convertirse en libre elector (sujeto observador ante la sociedad, y objeto que concita y sintetiza las miradas de otros en algún aspecto o condición, synopticon). En esta misma línea, el giro hacia la enunciación en primera persona de la web 2.o ha sido en ocasiones interpretado como una toma de la Bastilla de la producción de contenidos que, gracias a unos dispositivos instalados en la vida cotidiana y en los espacios íntimos, garantizaría el libre acceso y la libre creación frente a las grandes instituciones discursivas.

Desde el ámbito de la sociología, Castells y Douzinas (Marionitis, 2013, p. 101), han visto en la proliferación de las redes sociales un extraordinario potencial para la construcción de comunidades y para la democracia en un sentido sociológico que trasciende "los procesos instrumentales de elección y legitimación de las élites políticas” en paralelo a las dinámicas de "nacionalismo, racismo y xenofobia como productos del individualismo y del hueco que ha quedado entre ciudadanos y gobernantes" (idem.): "Democracy is more than a form of government; it is primarily a mode of associated living, of conjoint communicated experience" (Dewey, 2011, p. 90).

¿Qué tiene que ver la representación del cuerpo, del self, a través del autorretrato, en todos estos procesos participativos en la esfera pública? En la era del synopticon, absolutamente todo, siempre y cuando la mera anécdota devenga narración a través de una serie. Bajo este punto de vista, la capacidad de autorrepresentación consiste en que yo soy, al mismo tiempo, un voyeur y un icono para otros que sancionan positivamente expresando su 
adhesión, bien mediante un comentario, bien con la discreta fórmula de la herramienta "Like" o "Favorito". En este contexto, el silencio es altamente significante en tanto que adquiere el valor expresivo opuesto al de dicha adhesión.

En las aplicaciones y redes sociales de contactos para singles, por ejemplo, estamos ante el complejo problema de la elección frente a la persuasión. Como se ha visto a propósito de los autorretratos de lavabo y gimnasio, el self deviene icono en el selfie, de modo que, mostrando las virtudes corpóreas del individuo, se persigue el obvio propósito de la adhesión a través de la seducción. El sujeto lo hará con el rostro y, en ocasiones, con todo el cuerpo ante un espejo en el que el dispositivo fotográfico aparece como marca y garantía de autenticidad de aquella imagen. Entonces deviene porn star. Esta forma de representación del desnudo anula la expresividad al modo de un vaciado significante, esto es, la "profanación del erotismo" como insinuación o desvelamiento indicial del cuerpo deseado (Han, 2014, p. 50; Agamben, 2005, p. 97). No obstante conviene recordar que la imagen pornográfica, en tanto que está definida por su transparencia (el máximo grado de referencialidad que hace del dispositivo una mera -y necesaria- mediación que permite al voyeur un acercamiento discreto al objeto de su curiosidad) agrupa también bajo esta categoría de lo ilícito (no poder/ no deber ver) tanto a imágenes eróticas como aquellas otras de extraordinaria violencia. De ahí el peligroso carácter demostrativo y referencial de las imágenes de maltrato adolescente o el alto grado de verosimilitud de los vídeos propagandísticos (que no obstante deben ser verificados por las instituciones de vigilancia) en los que se muestran las brutales decapitaciones del Estado Islámico: "el FBI declaraba auténtico el vídeo de la decapitación de Foley, [entonces] el presidente Obama calificó el asesinato de brutal" (Monge, 2014). Aquí la forma de la expresión carece de importancia a la vista de un contenido terrible y tremendo.

De otra parte, la complejidad de la esfera pública como synopticon es mucho mayor cuando se considera la posibilidad de simulacro en función del principio de mise-en-scène en la imagen fotográfica. Así el embaucador 
Francisco Nicolás Gómez Iglesias ha logrado generar una identidad simulada al modo del Narcissus de Caravaggio: no correspondencia entre el original y el reflejo. Desde un punto de vista semiótico, el simulacro fotográfico generado por este estudiante de 20 años (Verdú, 2014) ha de ser clasificado dentro de la modalidad de la "mentira" (Greimas y Courtés, 1982, p. 434): aquella que en el esquema de la manifestación aparece como un "parecer" y en el de la inmanencia como un "no-ser". En dicha mentira (parece pero no es), el simulacro no surge de la expresión (utilizando una herramienta de postproducción por ejemplo) sino que está constituido por la imagen misma, tanto en su contenido como por aquella expresión que es interpretada como auténtica en función de su uso social vigente:

Su Facebook es un auténtico club de fans del PP -tiene como amigos diversos consejeros y asesores políticos- y un gran álbum de fotos con personalidades como Esperanza Aguirre, José María Aznar, Ana Botella o empresarios como Juan Miguel Villar Mir. Su última gran actuación fue en la coronación de Felipe VI, a la que asistió - nadie se explica ahora cómo lo hizo- y se hizo tomar la correspondiente fotografía dándole la mano al Rey. Una magnífica tarjeta de visita que, de nuevo, fue directa a las redes sociales (Verdú, 2014).

Aprovechando las propiedades antes enumeradas de "oportunidad" y “aparente inocencia” del selfie, Francisco Nicolás simula ser un personaje influyente y agente del Centro Nacional de Inteligencia. Sin embargo, cuando pasa a ser sancionada desde un juicio epistémico más profundo, la imagen termina siendo desenmascarada como "fraude" o con los términos jurídicos de "falsedad documental, estafa y usurpación de funciones públicas" (Huffington Post, 2014). Entonces, el gran interrogante de la fotografía y de la imagen en movimiento en la iconosfera digital es el del desplazamiento de su percepción o "actitud ante el texto" (Lotman, 2000, p. 199) como indicio (relación de contigüidad entre el referente-causante y el signo-resultante) hacia su construcción como icono o incluso como símbolo, en donde el signo, utilizando la terminología de Charles Morris, podría ser tan motivado como arbitrario. 
Por último, la autorrepresentación como parte de la gran categoría de la libertad de expresión, ha de convivir con otras manifestaciones discursivas aspectualizadas bajo la enunciación en primera persona que van desde la palabra escrita hasta el collage o el mashup de imágenes en movimiento, sean estas de naturaleza fotográfica o bien infografías o animaciones $2 \mathrm{D}$ y $3 \mathrm{D}$ ex novo, caso por ejemplo del avatar, de la ilustración, de la caricatura o de la marca generada por diseño gráfico digital.

De este hecho se desprende un régimen icónico de la saturación, en donde el libre acceso y el uso tanto tempestivo como intempestivo de la comunicación entran en conflicto con el concepto clásico de información. Bajo este punto de vista vale la pena recuperar los principios de la Teoría matemática de la comunicación por la que el mensaje informativo consiste en un cálculo de probabilidades (Lozano, 2006), o si quiere verse desde la Semiótica de la Cultura en el Lotman más informacional, se considerará un mensaje nuevo aquel que "no pueda ser deducido de manera unívoca con ayuda de algún algoritmo dado de antemano a partir de algún otro mensaje” (Lotman, 2000, p. 43). En consecuencia el signo icónico, en la saturación de la iconosfera digital, debe de asumir dos retos fundamentales: 1) competir desde un punto de vista formal contra la repetición de lo demasiado visto, de lo demasiado dicho, en donde debe señalarse por encima de la alta competencia (y es en este punto en donde surge el interés por lo implícito propio del estilo minimal frente a lo obvio de la imagen pornográfica transparente); y 2) disipar las dudas en torno a su autenticidad (que no originalidad, víd. Lozano, 2015) profundizando en las marcas de enunciación en primera persona inscritas en su interior.

\section{Referencias bibliográficas}

Agamben, G. (2005). Profanaciones. Buenos Aires: Adriana Hidalgo.

Altares, G. (24 de noviembre 2014). Los museos en la era del selfie. El País. Recuperado

de: http://cultura.elpais.com/cultura/2014/10/05/actualidad/1412517551_ 429563.html 
Aristóteles (1974). APIГTOTE Poetica. Poética de Aristóteles. Edición trilingüe por Valentín García Yebra. Madrid: Gredos.

Bentham, J. (1978). Bentham's theory of the Modern State. London: Harvard University Press.

Benveniste, É. (1977): Problemas de lingüística general II. Madrid: Siglo XXI.

Canga Sosa, M. (2015). Introducción al fenómeno del Selfie: valoración y perspectivas de análisis. FOTOCINEMA. Revista científica de cine y fotografía, 10, pp. 383-405.

Cardona Echeverri, J. (2013). Instagram y la nostalgia sintética. Revista Universidad de Antioquia, 312, pp. 66-68.

Dewey, J. (2011). Democracy and Education: An Introduction to the Philosophy of Education. South Carolina: Simon and Brown.

Eco, U. (2003). Apocalípticos e integrados. Traducción de Andrés Boglar. Barcelona: Lumen.

Fontanille, J. (2014). Semióticas de la transparencia. En Lozano, J. (ed.) (2014), Secretos en red. Intervenciones semióticas en el tiempo presente (pp. 141-160). Madrid: Sequitur.

Foucault, M. (1994). Vigilar y castigar: nacimiento de la prisión. Madrid: Siglo veintiuno.

Graves, R. (1985). Los mitos griegos. Barcelona: Ariel.

Gubern, R. (9 de septiembre 2009). Democracia informativa no es excelencia. Recuperado de:

http://www.fondodeculturaeconomica.com/editorial/prensa/Detalle.as px?seccion=Detalle\&id_desplegado $=29044$

Han, B.-Ch. (2014). La agonía del Eros. Barcelona: Herder.

Herrán Ortiz, A. I. (29 de septiembre 2014). Derecho a ser olvidados. El País. Recuperado

de: http://ccaa.elpais.com/ccaa/2014/o9/29/paisvasco/1412002211_7481 61.html

Homero (1998). La Ilíada. Texto, traducción y notas por José García Blanco y Luis M. García Aparicio. Vol. II Cantos IV-IX. Madrid: CSIC.

Huffington Post (2014). Francisco Nicolás Gómez Iglesias, en libertad. The Huffington Post. Recuperado de: http://www.huffingtonpost.es/2014/10/17/francisco-nicolaslibertad_n_6002336.html

Jakobson, R. (1984). Ensayos de lingüística general. Barcelona: Seix Barral.

Levin, A. (2014). The Selfie in the age of Digital Recursion. InVisible Culture: An Electronic Journal for Visual Culture (IVC). Recuperado de: 
http://ivc.lib.rochester.edu/portfolio/the-selfie-in-the-age-of-digitalrecursion/

Lotman, Y. M. (1998). Cultura y explosión. Lo previsible y lo imprevisible en los procesos de cambio social. Barcelona: Gedisa.

Lotman, Y. M. (2000). La semiosfera I. Madrid: Cátedra.

Lozano, J. (2006). Información: la diferencia que hace diferencia. En recuerdo de Ludwig Boltzmann (1844-1906). Revista de Occidente, 296, pp. 119-125.

Lozano, J. (2015). Lo auténtico no es único, pero aun así... Revista de Occidente, 404, pp. 5-14.

Lyon, D. (2006). 9/11, Synopticon, and Scopophilia: Watching and being Watched. En Ericson, R. V. y Hagerty, K. D. (2006). New Politics of Surveillance and Visibility (pp. 35-53). Toronto: University of Toronto Press.

Mathiesen, T. (1997). The Viewer Society: Michel Foucault's Panopticon Revisited. Theoretical Criminology, vol. 1, pp. 215-232.

Marionitis, K. (2013). Like, comment, share: belonging and exclusion in the protest community. IC Journal, 10, pp. 99-119.

Monge, Y. (3 de septiembre 2014). El Estado Islámico decapita a otro periodista estadounidense. El País. Recuperado de: http://internacional.elpais.com/internacional/2014/09/02/actualidad /1409677987_899560.html

Ovidio Nasón, P. (2004): Metamorfosis. Santa Fe (Argentina): El Cid Editor.

Segarra Valls, J. J. (2010). Léxico(psico)patológico en la obra de Carlos Castilla del Pino. Valencia: Universidad de Valencia.

Sófocles (2014). Edipo Rey. Costa Rica: Vi-Da Global.

Vázquez Medel, M. A. (2003). Teoría del emplazamiento: aplicaciones e implicaciones. Sevilla: Alfar.

Verdú, D. (17 de octubre 2014). La gran estafa del pequeño Fran. El País. Recuperado

de: http://politica.elpais.com/politica/2014/10/17/actualidad/1413550907 _840993.html

Cómo citar: Broullón-Lozano, M. A. (2015). "Por una semiótica del selfie en la cultura visual digital". Fotocinema. Revista científica de cine y fotografía, 11, pp. 215-234. Disponible: http://www.revistafotocinema.com/ 